\title{
Clinical and Para Clinical Manifestations of HIV-Positive Patients at Different Levels of CD4
}

\author{
Fariba Keramat ${ }^{1}$, Parisa Hamzeloui ${ }^{2}$, Mohammad Ali Seif Rabiei ${ }^{3}$, Ali Saadatmand ${ }^{4, *}$ \\ ${ }^{1}$ Professor, Brucellosis Research Center, Hamadan University of Medical Sciences, Hamadan, Iran \\ ${ }^{2}$ General Practitioner, School of Medicine, Hamadan University of Medical Sciences, Hamadan, Iran \\ ${ }^{3}$ Associate Professor, Department of Social Medicine, Hamadan University of Medical Sciences, Hamadan, Iran \\ ${ }^{4}$ MSc in Microbiology, Brucellosis Research Center, Hamadan University of Medical Sciences, Hamadan, Iran \\ * Corresponding Author: Ali Saadatmand, Brucellosis Research Center, Hamadan University of Medical Sciences, \\ Hamadan,Iran.Email: Ali.s_umsha@yahoo.com
}

Received: 28.04 .2019

Accepted: 19.08 .2019

How to Cite this Article:

Keramat F, Hamzeloui P, Seif

Rabiei MA, Saadatmand A.

Clinical and Para Clinical

Manifestations of HIV-Positive

Patients at Different Levels of

CD4. Avicenna J Clin Med.

2019; 26(2): 110-117. DOI:

$10.21859 / \mathrm{ajcm} .26 .2 .110$

\section{Abstract}

Background and Objective: Human immunodeficiency virus (HIV)infected people are at higher risk of opportunistic infections due to immunodeficiency. The current study aimed to evaluate the different levels of CD4 in HIV-infected patients and its relationship with clinical and paraclinical manifestations of the patients.

Materials and Methods: This cross-sectional study was conducted on 94 HIV-infected patients referred to the Counseling Centers for Behavioral Diseases and Sina Hospital in Hamadan, from 2014 to 2015. At the commencement of the study, written consent was obtained from the participants. Thereafter, demographic data, history of underlying diseases, symptoms and clinical syndromes, medical history, and serum CD4 levels were evaluated by flow cytometric recorded in the questionnaire and data were analyzed in SPSS software(version 16).

Results: Out of 66 HIV-positive patients, $70.2 \%(n=38)$ were male and the mean age of the patients was $40.06 \pm 10$. 04 years. In terms of classification of the clinical stage of the disease, the patinets in the first, second, and third stages were reported as $11(11.7 \%), 36(38.3 \%)$ and $34(36.2 \%)$, respectively. The mean serum CD4 count of the patients at the beginning of antiretroviral therapy was measured at $284.241 \pm 284$ and $377.19 \pm 271.41$ cells $/ \mu 1$, respectively. The difference in the mean of serum CD4 count before and after antiretroviral therapy was revealed to be statistically significant $(\mathrm{P}=0.001)$. The most common clinical symptoms observed included cough and sputum (29.9\%), oral aphthous ulcer (12.7\%), weight loss (11.7\%), and fever (7.4\%). Based on the results of the study, there was a significant difference between the mean of platelet count, hemoglobin and alkaline phosphatase at different levels of CD4 $(\mathrm{P}<0.05)$.

Conclusion: According to the results of the present study, serum CD4 levels rise with the initiation of antiretroviral therapy in HIV infected patients; therefore, early antiretroviral therapy in HIV-infected patients with any serum CD4 level is of paramount importance.

Keywords: Clinical Manifestations, Human Immunodeficiency Virus, Serum Level 


\section{تظاهرات بالينى و ياراكلينيكى بيماران HIV مثبت در سطوح مختلف CD4}

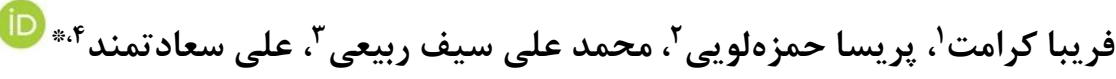

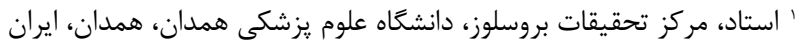

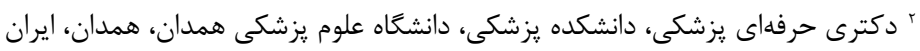

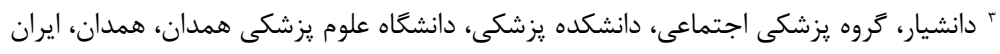

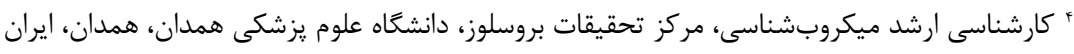

Ali.s_umsha@yahoo.com : نويسنده مسئول: على سعادتمند، مركز تحقيقات بروسلوز، دانشكاه علوم يزشكى همدان، همدان، ايران. ايميل *

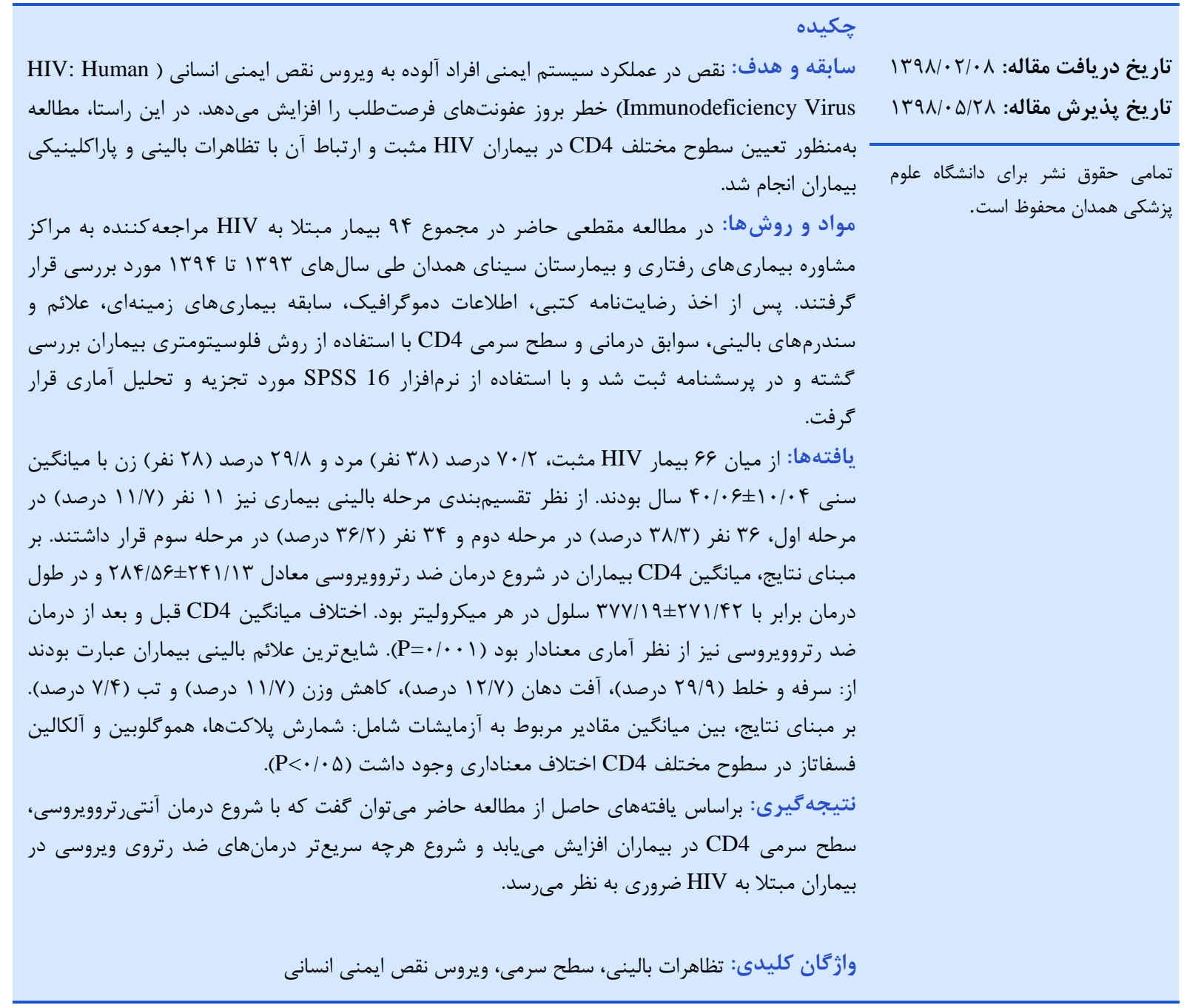

مقلدمه

مختلف، اين بيمارى بهعنوان يك همهكيرى جهانى شناخته شده

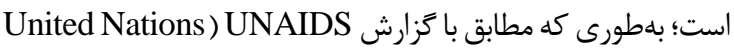
تا تا (Program Acquired Immune Deficiency Syndrome

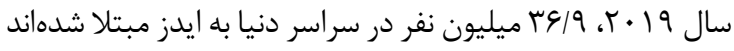

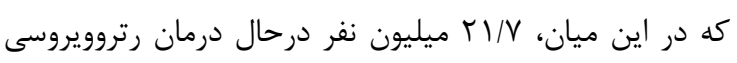

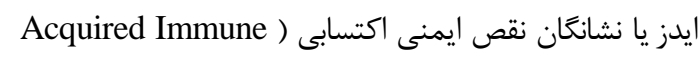
از جمله بيمارىهاى مهرم عفونى (Deficiency Syndrome

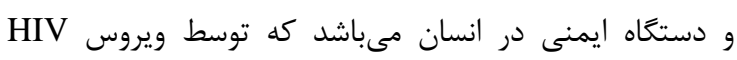
(Human Immunodeficiency Virus) در حال حاضر با گسترش روزافزون بيمارى ايدز در جوامع 
بلهور كلى علائم بالينى عفونت HIV را مى توان به سه

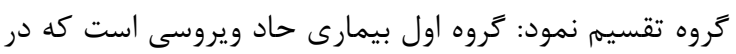

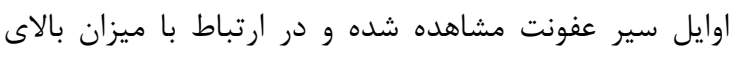

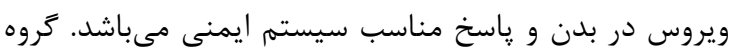

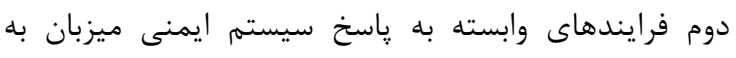

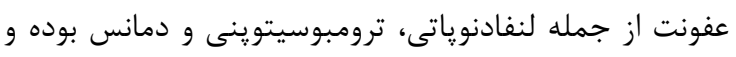
كروه سوم بيمارىهاى فرصتطلب ناشى از تخريب سيستم ايمنى ميزبان كه مشخصه بارز بيمارى ايدز مى باشند، هستند

بلهور معمول در نخستين ويزيت بيمار مىبايست تعداد

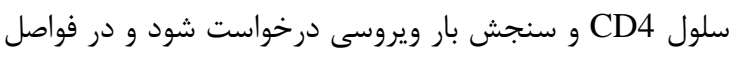

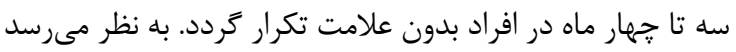

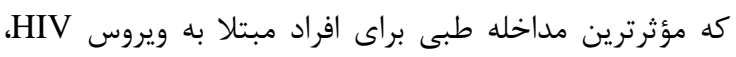

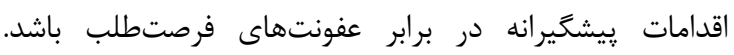

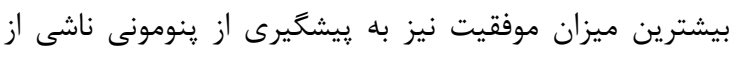

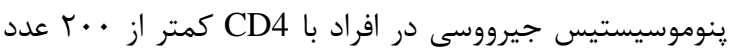

در ميلى متر مكعب اختصاص دارد [1]].

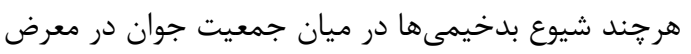

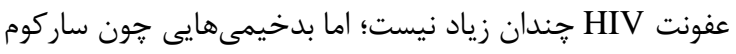

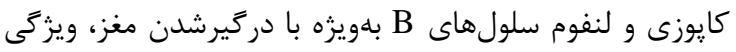

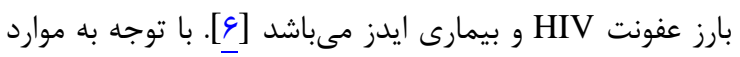

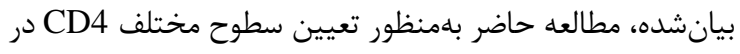

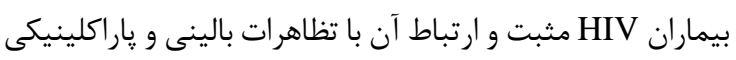

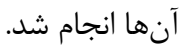

\section{مواد و روشها}

در مطالعه مقطعى حاضر كه به روش سرشمارى از ابتداى

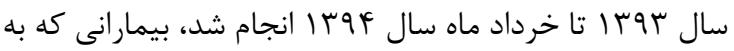

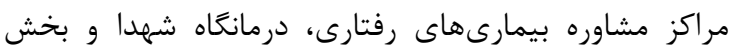

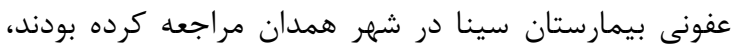

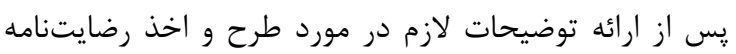

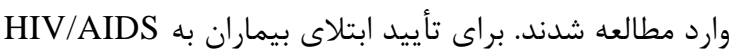

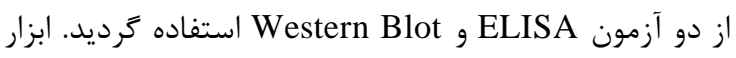
جمعآورى اطلاعات در اين مطالعه، يرسشنامهاى شامل: تاريخ

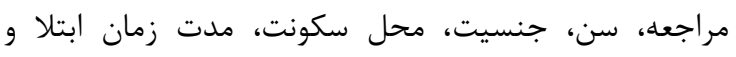

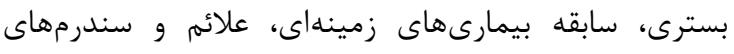

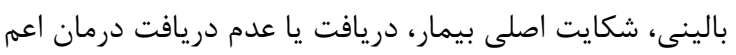

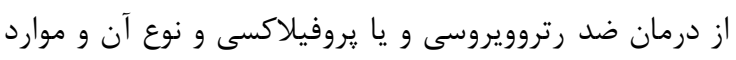
آزمايشگاهى بود. تقسيمبندى مراحل بيمارى

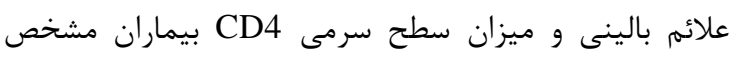

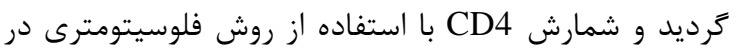

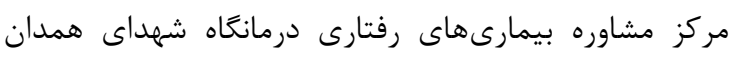

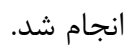

در انتها، دادهاى بلهدستآمده با استفاده از نرمافزار

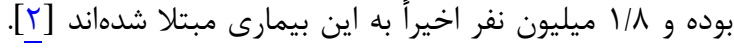

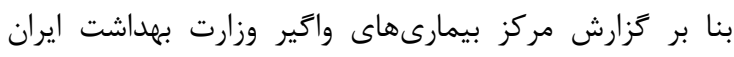

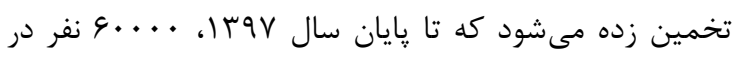

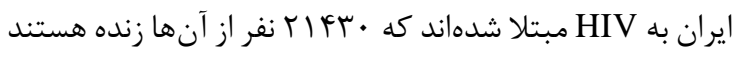

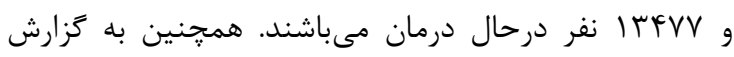

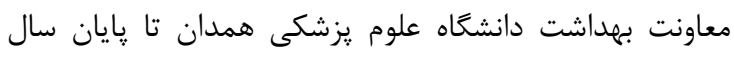

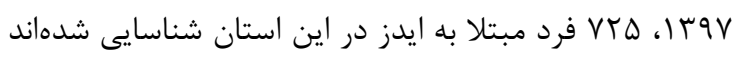
كه از اين تعداد هاس نفر فوت شده و

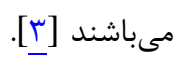
سيكل همانندسازى HIV با اتصال يروتئين اصلى سطحى

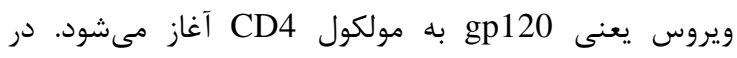
حقيقت، CD4 يك يروتئين است كه در سطح لنفوسيتهاى مشاهده مى شود و نقش مهميى را در ايمنى هومورال

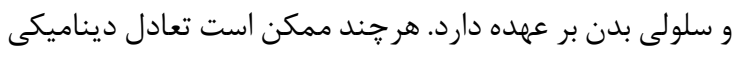
به مدت جندين سال بين سلولهاى CD4 و

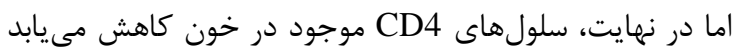

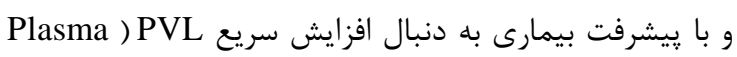

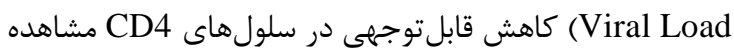

مىشود [lic]. اختلالات شديد و متعدد در سيستم ايمنى فرد سبب

افزايش خطر بروز عفونتهاى فرصتطلب در افراد آلوده به فيه HIV

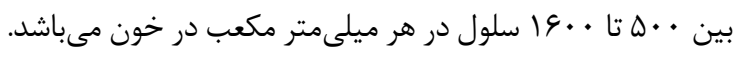

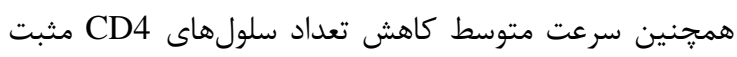
بلهور ميانگين در حدود •ه عدد در هر ميكروليتر در هر سال

است [1]

Centers for) CDC سيستم طبقهبندى فعلى HIV افراد مبتلا به (Disease Control and Prevention را براساس شرايط بالينى و تعداد لنفوسيتهاى CD4 مثبت به جهار گروه تقسيه مى كند. گرروه اول بيمارانى هستند كه

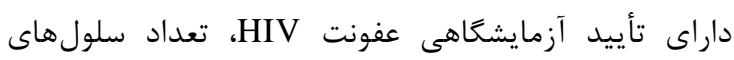

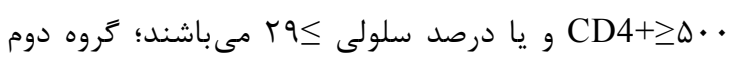

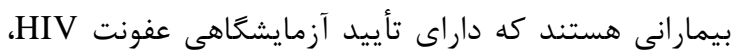

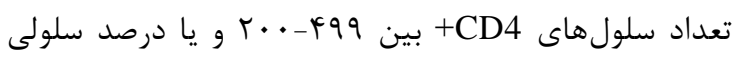

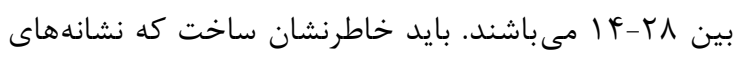

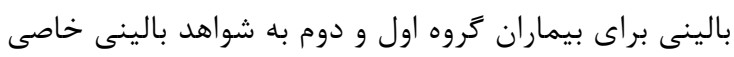
نياز ندارد و لازم است كه تنها شامل تعاريف ايدز نباشد؛ كرو بروه

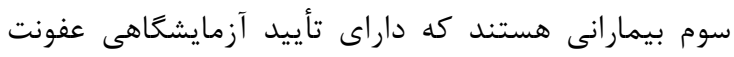

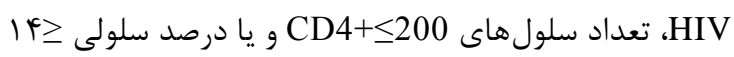
با شواهد بالينى كه در تعريف ايدز بخَنجند، هستند؛ كروه

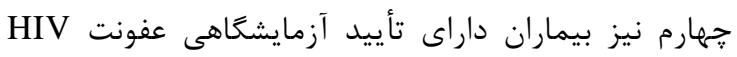

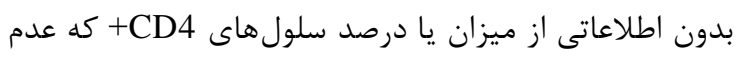

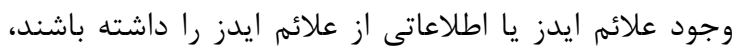

مى باشند [F] 
ميانگين سطح سرمى CD4 بيماران HIV مثبت در مرحله

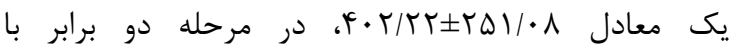

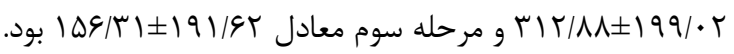

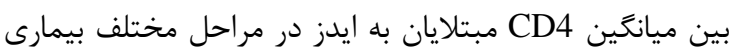

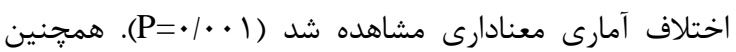

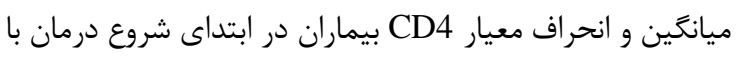

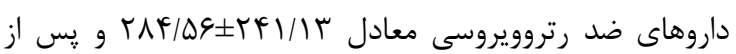

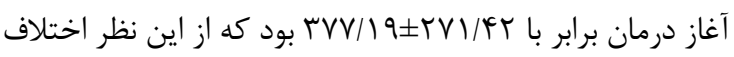

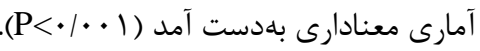

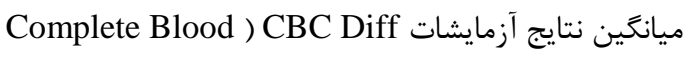

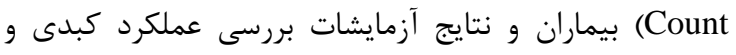

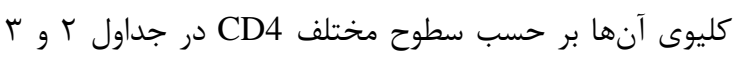
مشاهده مىشود. بر مبناى نتايج، بين ميانگين مقادير مربوط به به آزمايشات

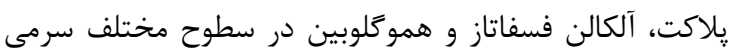
CD4 اختلاف معنادارى مشاهده شد (ه • P (P).

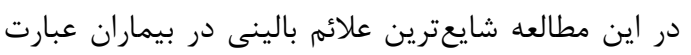

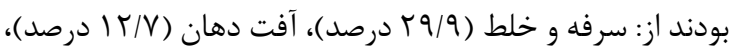

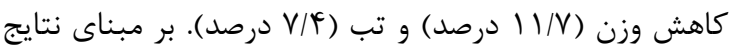

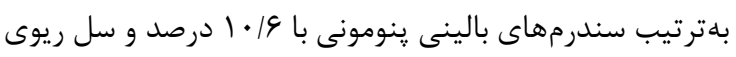

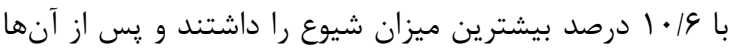

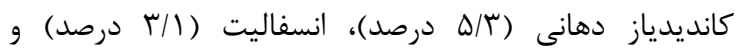

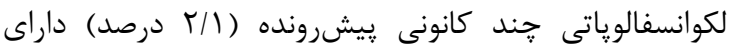
بيشترين ميزان شيوع بودند. اين موارد با توجه به اطلاعات و دونئن

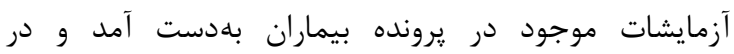

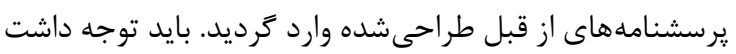

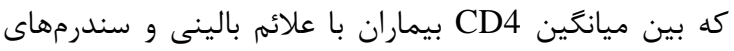

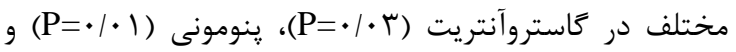

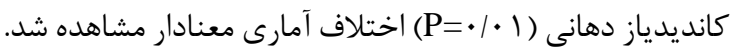

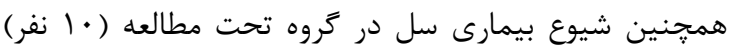

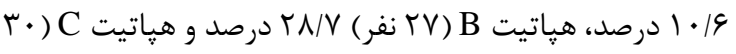

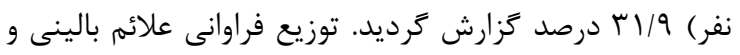
F مثبت بلهترتيب فراوانى در جدول

$$
\text { مشخص شده است. }
$$

تجزيه و تحليل گرديدند و براى تعيين ارتباط بين SPSS 16

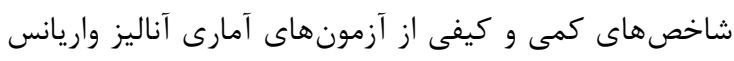

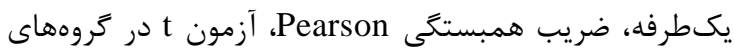
غيرهمبسته و مجذور كاى استفاده شد.

\section{كافتهن}

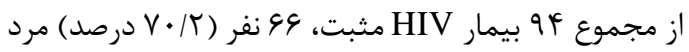

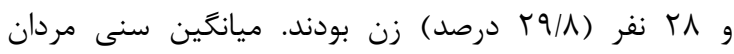

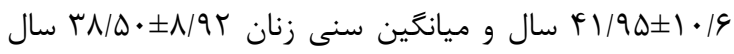

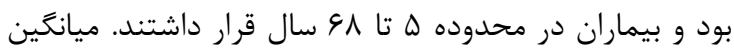

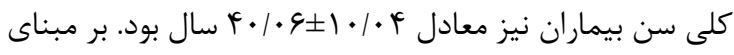

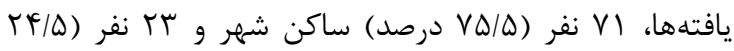

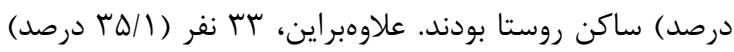

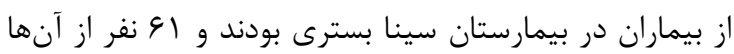

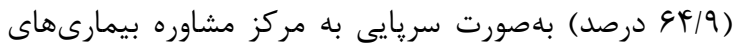

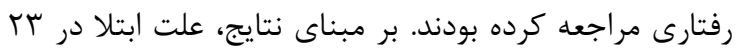

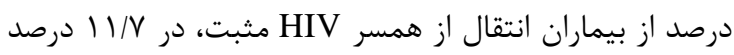

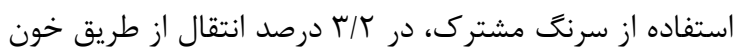

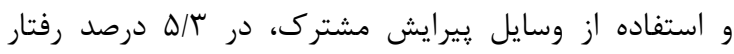

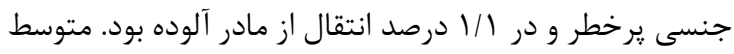

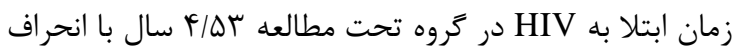

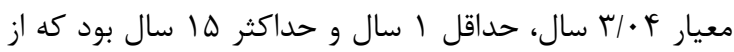
نظر آمارى معنادار نبود (P= (PS).

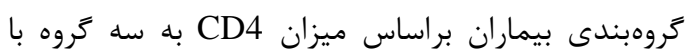

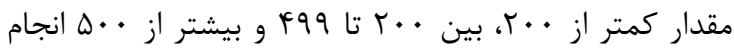

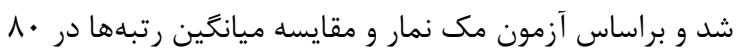

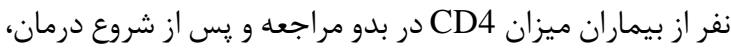

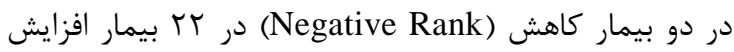
(Positive Rank)

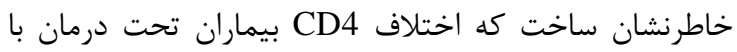

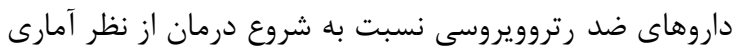
معنادار بود (P=-F)

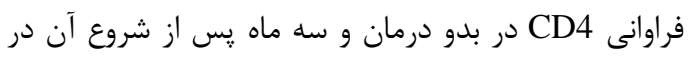
بيماران HIV مثبت در جدول ا نشان داده شده است.

جدول ا: مقايسه توزيع فراوانى CD4 بدو درمان و سه ماه يس از شروع درمان در بيماران HIV مثبت

\begin{tabular}{|c|c|c|}
\hline سه ماه يس از درمان & تعداد (درصد مراجعه & سطح سرمى سلول بر ميكروليتر CD4 \\
\hline$(r q / \Lambda) \Gamma \Lambda$ & (TG/T) rF & $<r_{.}$. \\
\hline$(T r / V) T \omega$ & צ $(\Psi / \Gamma)$ & r..- $\$ 9 q$ \\
\hline$(r q / \wedge) \Gamma \wedge$ & $(11 / V) 11$ & $>\Delta .$. \\
\hline$(r / T) r$ & r| (I/A) & نامعلوم \\
\hline$(1 \cdots) 9 F$ & $(1 \cdots) q f$ & جمع \\
\hline
\end{tabular}


جدول r: توزيع فراوانى ميانخين نتايج آزمايشات CBC Diff بر حسب سطوح مختلف CD4 در بيماران HIV مثبت

\begin{tabular}{|c|c|c|c|c|c|}
\hline سطح معنادارى & 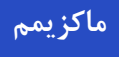 & مينيمم & ميانگين & سطح سرمى سلول بر ميكروليتر CD4 & آزمايشات باراكلينيك \\
\hline \multirow{3}{*}{$\cdot / V I$} & $10 \cdots$ & Ir.. & $\Delta \Delta \& 1$ & $\cdot-199$ & \multirow{3}{*}{ (....>مارش لكوسيت } \\
\hline & $1 \Delta r \ldots$ & $r V$. & $4.9 \mathrm{~V}$ & $r \cdots r q q q$ & \\
\hline & १६.. & FF.. & gft. & $>\Delta \ldots$ & \\
\hline \multirow{3}{*}{$\cdot / T V$} & $\%$. & $\%$ & (t) & $\cdot-199$ & \multirow{3}{*}{ شمارش لنفوسيت (...ميكروليتر) } \\
\hline & $\% \vee \Delta$ & $\%$ lf & $\%$. & $r \ldots r q q$ & \\
\hline & $\% \Delta \varphi$ & $\%$ / T & $\%$ & $>0 \cdots$ & \\
\hline \multirow{3}{*}{$\cdot / \cdot r$} & 19 & v & $\mid r / \cdot 9$ & $\cdot-199$ & \multirow{3}{*}{ (كمرم بر دسبين } \\
\hline & $\mid 9 / 4$. & $9 / 1$. & $\mid r / \Delta \varphi$ & $r \cdots r q q$ & \\
\hline & $1 F / V$ & 11 & $\mid r / \cdot V$ & $>\Delta \ldots$ & \\
\hline \multirow{3}{*}{$\cdot 1 \cdot r$} & FV & rI & TV/TG & $\cdot-199$ & \multirow{3}{*}{ 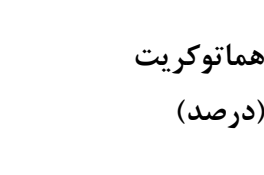 } \\
\hline & $q \vee / Q$. & m & $r \cdot / V r$ & $r \cdots-r q q$ & \\
\hline & FT/F. & r/Tl & re/TV & $>\Delta \cdot$. & \\
\hline \multirow{3}{*}{$\cdot 1 \cdot r$} & rFa... & $\Delta \cdots$ & $1 \wedge 9 \ldots$ & $\cdot-199$ & \multirow{3}{*}{ بلاكت (... (ميكروليتر) } \\
\hline & $p \Delta q \ldots$ & $1 \cdots$ & 1ятद.. & $r \cdots r q q$ & \\
\hline & rfl... & $18 \cdots$ & $I V \Delta F \Delta \Delta$ & $>\Delta \cdots$ & \\
\hline
\end{tabular}

جدول سا: توزيع فراوانى ميانكين نتايج آزمايشات بررسى عملكرد كبدى و كليوى بر حسب سطوح مختلف CD4 در بيماران HIV مثبت

\begin{tabular}{|c|c|c|c|c|c|}
\hline سطح معنادارى & ماكزيمم & مينيمم & ميانگين & مقدار CD4 & آزمايشات \\
\hline \multirow{3}{*}{$\cdot / \mu F$} & IDF & $\wedge$ & GY/GF & $\cdot-199$ & \multirow{3}{*}{$\begin{array}{r}\text { ALT } \\
\text { (واحد بر ليتر ) }\end{array}$} \\
\hline & $\mid 91$ & 1 . & TQ/TT & $r \cdots-r q q$ & \\
\hline & 99 & IV & $r / / \Delta$. & $>\Delta \ldots$ & \\
\hline \multirow{3}{*}{.1 .9} & $1 \cdot 9$ & ir & $r q / G q$ & $\cdot-199$ & \multirow{3}{*}{$\begin{array}{r}\text { AST } \\
\text { (واحد بر ليتر ) }\end{array}$} \\
\hline & 195 & 1 . & $F r / Q F$ & $r \cdots-r q q$ & \\
\hline & $r \cdot$. & If & $99 / 1$. & $>\Delta \cdots$ & \\
\hline \multirow{3}{*}{$\cdot / \cdot r$} & $1 \cdot \Delta r$ & 110 & $r Q \Delta / r T$ & $\cdot-199$ & \multirow{3}{*}{$\begin{array}{r}\text { ALKP } \\
\text { (واحد بر ليتر ) }\end{array}$} \\
\hline & . & FV & 198/9V & $r \cdots-r q q$ & \\
\hline & FDV & $11 \mathrm{~V}$. & TVT & $>\Delta \cdots$ & \\
\hline
\end{tabular}

جدول F: توزيع فراوانى علائم بالينى و CD4 در بيماران HIV مثبت

\begin{tabular}{|c|c|c|c|c|c|}
\hline سطح معنادارى & •.. ه و بالاتر & $\begin{array}{r}\text { CD4 } \\
r . \bullet-p q q\end{array}$ & كمتر از 199 & تعداد كل & علائم بالينى \\
\hline$\cdot / 14$ & f & v & IV & $r \wedge$ & سرفه و خلط \\
\hline .19 & r & f & 4 & it & آفت دهان \\
\hline$\cdot / \mu F$ & 1 & r & $\wedge$ & 11 & كاهش وزن \\
\hline$\cdot 1 \cdot 1$ & . & r & v & 1. & 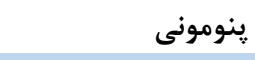 \\
\hline$\cdot / r$ & 1 & r & f & v & 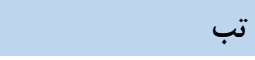 \\
\hline$\cdot / \cdot r$ & · & r & f & 4 & اسهال و استفراغ \\
\hline$\cdot 199$ & · & r & r & 9 & كبودى اندام \\
\hline$\cdot / 199$ & · & · & $\Delta$ & $\Delta$ & ترشحات پشت حلق \\
\hline$\cdot / T V$ & r & 1 & r & $\Delta$ & هإيول يوستى \\
\hline$\cdot 1 \cdot 1$ & 1 & 1 & r & $\Delta$ & كانديدياز دهانى \\
\hline
\end{tabular}




\begin{tabular}{|c|c|c|c|c|c|}
\hline & & & & & ادامه جدول F. \\
\hline$\cdot / \pi \omega$ & . & · & r & r & افسردگى \\
\hline$\cdot 1 \cdot 1$ & 1 & $\cdot$ & r & r & آنمى \\
\hline$\cdot 19$ & $\cdot$ & 1 & r & r & انسفاليت توكسويلاسمايى \\
\hline$\cdot \operatorname{st}$ & $\cdot$ & $\cdot$ & r & r & لكوانسفالوياتى جند كانونى يِيشرونده \\
\hline$\cdot 11$ & $\cdot$ & $\cdot$ & 1 & 1 & 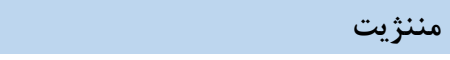 \\
\hline$\cdot / D F$ & $\cdot$ & $\cdot$ & 1 & 1 & كَاستروانتريت كريِتوسيوريديا \\
\hline
\end{tabular}

اختلاف، جامعه و مكان مورد مطالعه باشد.

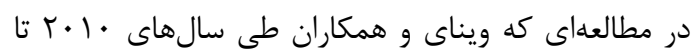

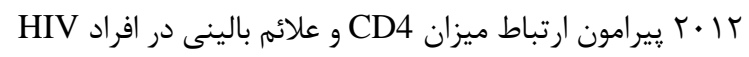

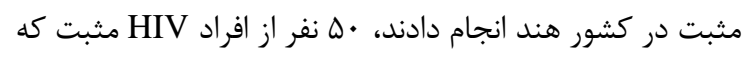
سن بيش از 19 سال داشتند، وارد مطالعه شدند. در اين مطالعه

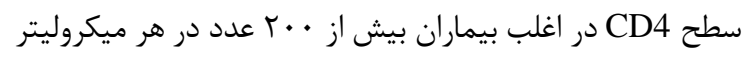

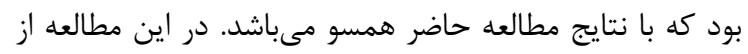

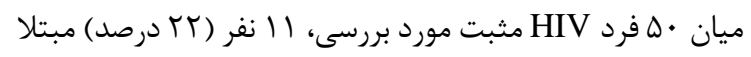

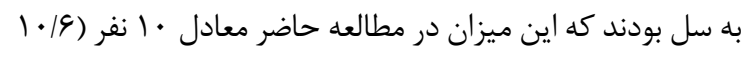

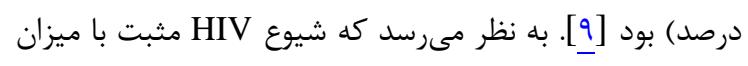

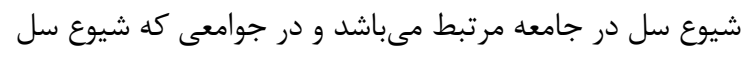
بالاتر است، HIV مثبت شيوع بيشترى دارع دارد.

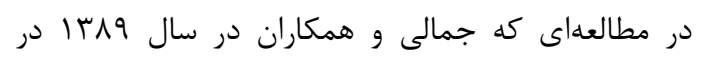

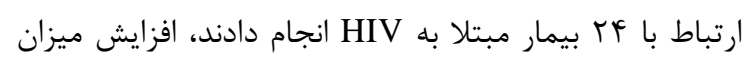

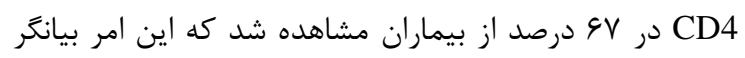

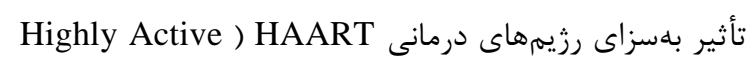

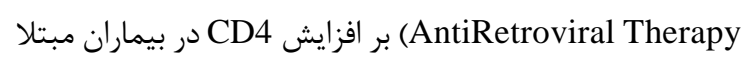

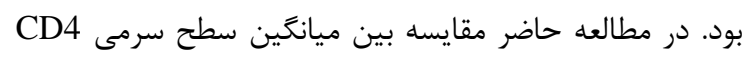

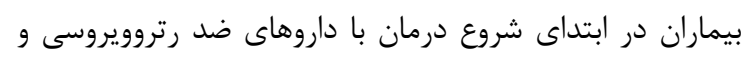

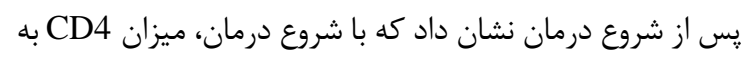

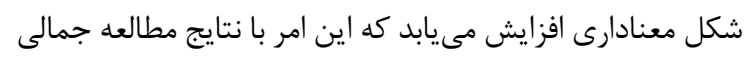

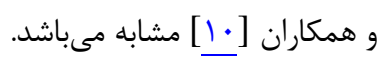

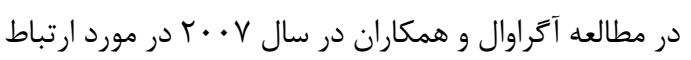
علائم HIV و شدت و درجه نقص ايمنى در كودكان مبتلا به HIV

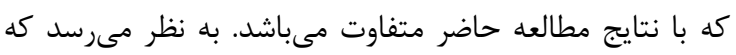
علت اين تفاوت، اختلاف سنى بيماران مورد بررسى باشد [11].

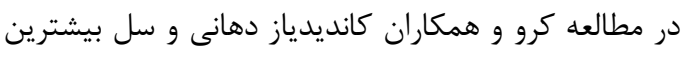

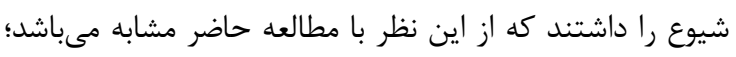

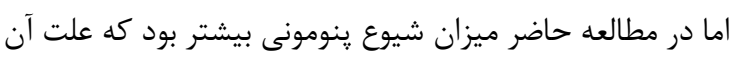

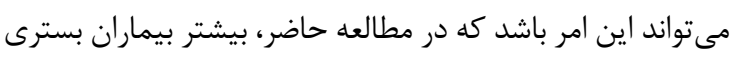

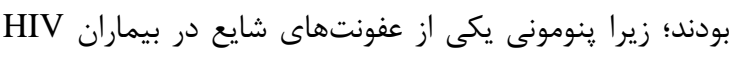

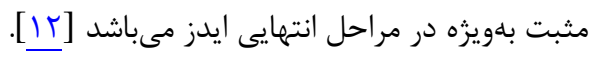

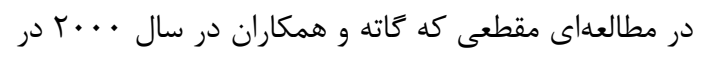

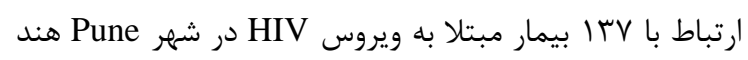

ايدز از جمله بيمارىهاى مههم عفونى مىباشد كه باعث

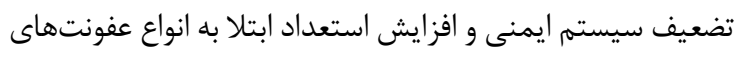
فرصتطلب و بدخيمى ها مىشود. عفونت HIV با يِيشرفت خود إنى

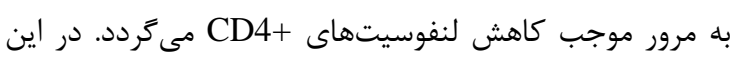
راستا در مطالعهاى كه توسط محرز و همكاران در تهران انجام

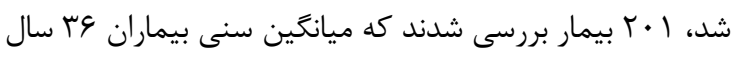

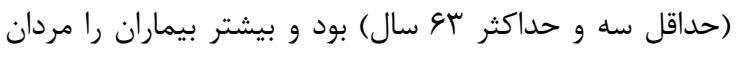

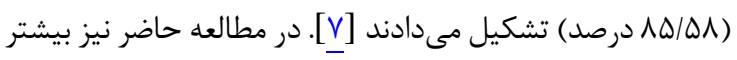

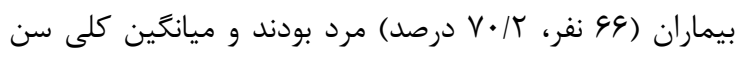

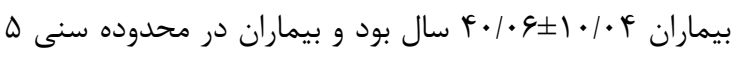
تا 4 سال قرار داشتند. همجنين در مطالعهاى كه داوودى و و

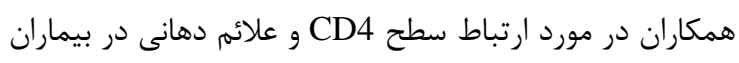

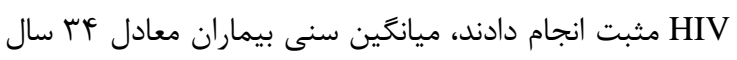

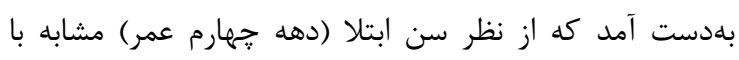

يافته هاى مطالعه حاضر بود [^].].

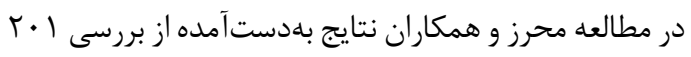

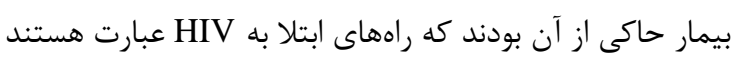

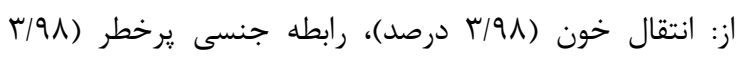

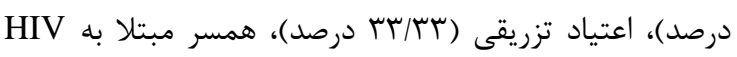

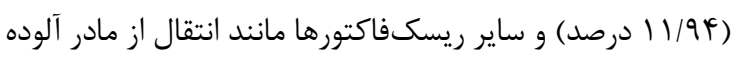

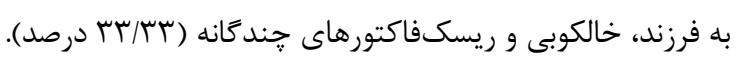
همجنين داوودى و همكاران مطالعاتى را يِيرامون ارتباط سطح

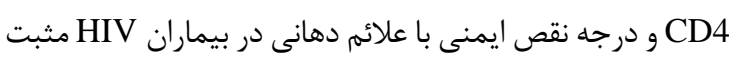

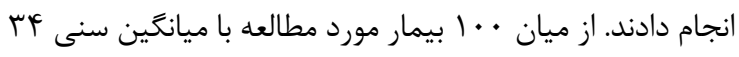

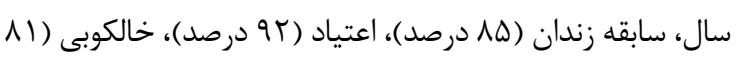

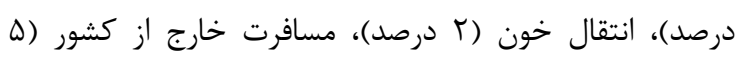

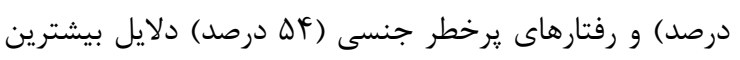

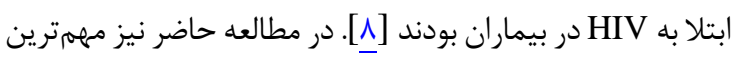

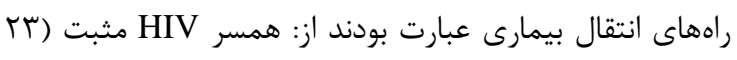

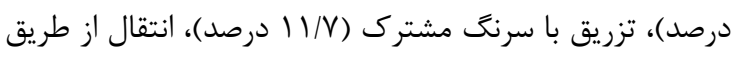

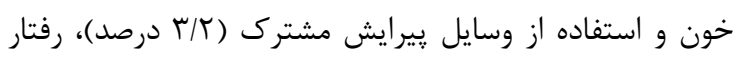

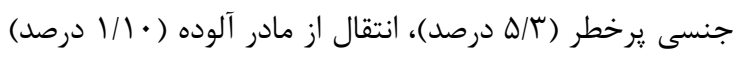

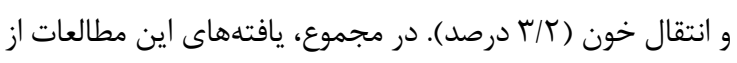

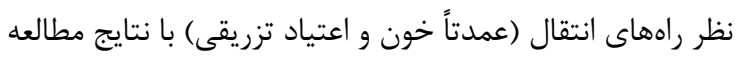

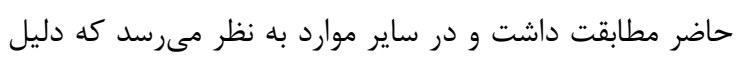


در اين مطالعه شايعترين روش آلودگى، انتقال يرىناتال از مادر آلوده بود. همجنين علائمى إنى لودئ (Vertical Transmission) جون تب، اسهال، سرفه و لنفادنوياتى شايعترين علائم در ميان

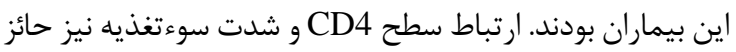

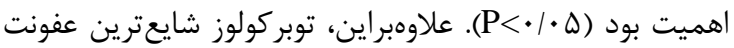

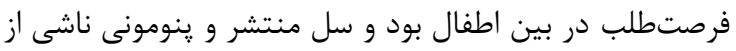
ينوموسيستيس جيرووسى در بين عفونتها از كمترين ميزان

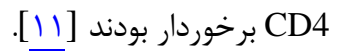

\section{نتيجه تيرى}

با شروع درمان آنتىرتروويروسى، سطح CD4 بيماران به

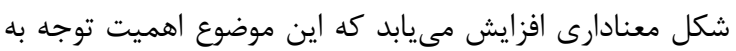

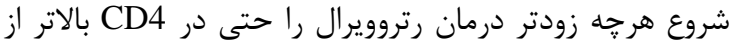

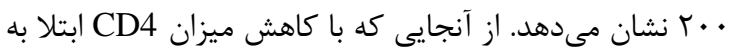

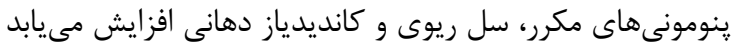

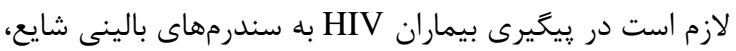

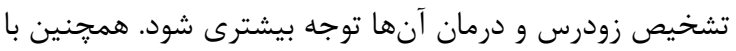

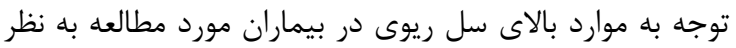

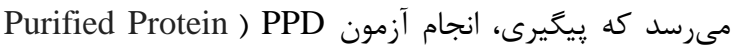

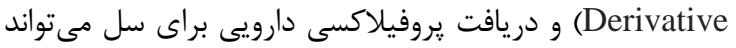

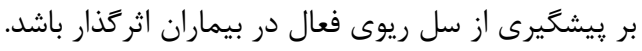

\section{تشكر و قلروفاذى}

مقاله حاضر بركرفته از ياياننامه دكترى حرفهاى يزشكى

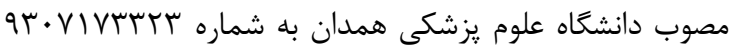

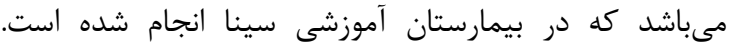

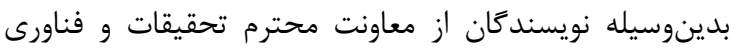

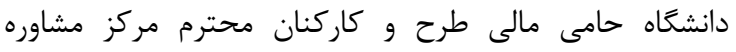

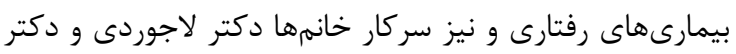
نيكبخت تشكر و قدردانى مىنمايند. نتايج اين مطالعه با منافع

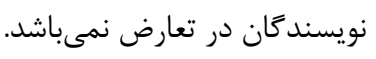

\section{REFERENCES}

1. Beckwith C, Wing E, Rodriduez B, Lederman M. Human immunodeficiency virus infection and acquired immunodeficiency syndrome. In: Androeli T, Griggs R, Wing E, editors. Andreoli and Carpenter's cecil essentials of medicine e-book: with student consult online access. Philadelphia: Elsevier Health Sciences; 2010. P. 1008-27.

2. Aids and the sustainable development goals. UNAIDS. Available at: URL: http://www.unaids.org/en; 2019.

3. Hygiene health. Ministry of Health and Medical Education. Available at: URL: http://health.behdasht.gov.ir; 2019.

4. Lane HC, Fauci AS. Human immunodeficiency virus disease: AIDS and related disorders. In: Fauci AS, Kasper DL, Longo DL, editor. Harrison's principle of internal medicine. New York: MacGraw-Hill; 2011. P. 1137-203.

5. Sterling TR, Chaisson RE. General clinical manifestation of HIV infection (including the acute retroviral syndrome and oral, cutaneous, renal, ocular, metabolic and cardiac disease. $7^{\text {th }}$ ed. London: Churchill Livingstone; 2010. P. 1705-25.

6. Cleghorn FR, Reitz MS, Popovic M, Gallo RC. Human
انجام دادند، به اين نتيجه رسيدند كه سطح CD4 به شكل

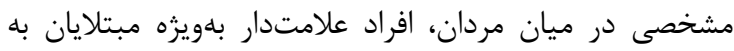

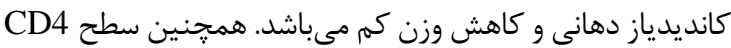
بهطور روشنى در افراد علامتدار بلويزه مبتلايان به كانديدياز

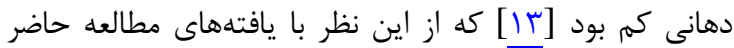

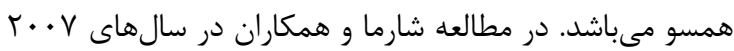

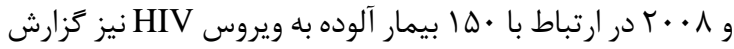

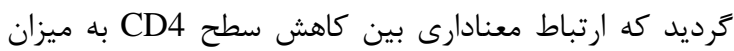

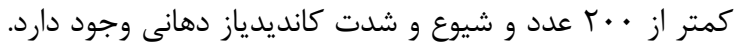

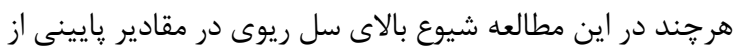

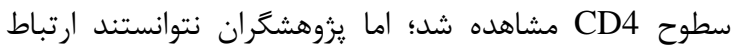

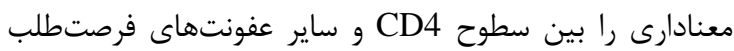

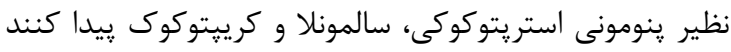

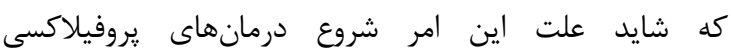

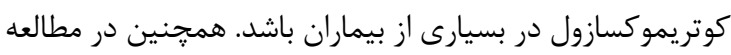

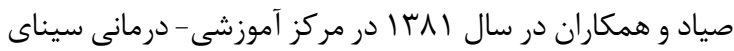

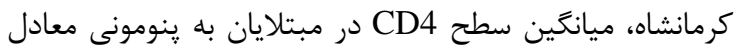

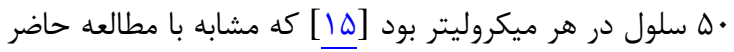
بين ينومونى و سطح CD4 رابطه معنادارى وجود داشت.

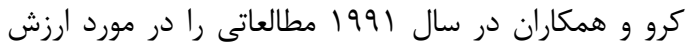
اخبارى ارتباط سطح CD4 با عفونتهاى فرصتطلب و و و بدخيمى دها

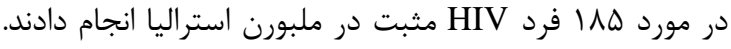

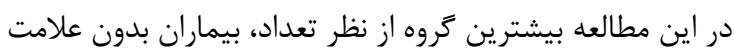

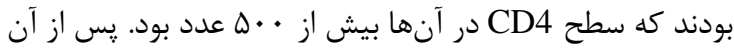

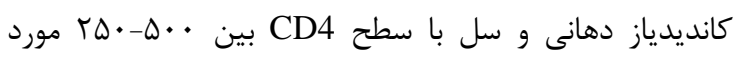
بيشترين شيوع را داشتند. كرو و همكاران ييشنههاد دادند كه آغاز

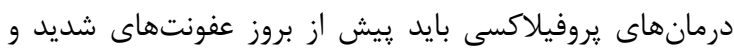

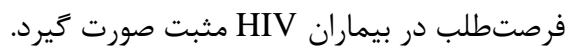

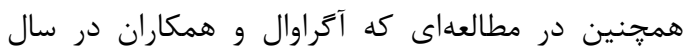

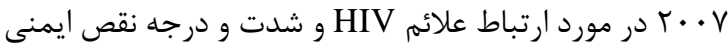
در كودكان مبتلا به HIV انجام دادند، تعداد افراد مورد مطالعه

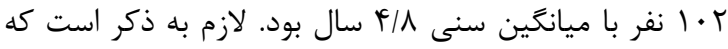

immunodeficiency viruses. Bennett's principles and practice of infectious diseases. $6^{\text {th }}$ ed. Philadelphia: Churchill Caurehill Livingston; 2010. P. 1012-4.

7. Mohraz M, Mehrkhani F, Jam S, SeyedAlinaghi S, Sabzvari D, Fattahi F. Seroprevalence of toxoplasmosis in HIV(+)/AIDS patients in Iran. Acta Med Iran. 2011; 49(4):213-8. PMID: 21713730

8. Davoodi P, Hamian M, Nourbaksh R, Ahmadi Motamayel F. Oral manifestations related to CD4 lymphocyte count in HIVpositive patients. J Dent Res Dent Clin Dent Prospects. 2010;4(4):115-9. PMID: 23346337 DOI: 10.5681/joddd. 2010.029

9. Vinay KV, Sandeep GN, Vishal K, Beena DN. Study of the relationship between CD4 count and clinical features in HIV infected patients in South Indian population. Indian J Fund Appl Life Sci. 2012;2(3):153-61.

10. Jamali E, Vahdat K, Hodavand F. Evaluation of influence of HAART on HIV positive patients in Bushehr hospital. Iran South Med J. 2014;14(3):17-9. [Persian] 
11. Agarwal D, Chakravarty J, Sundar S, Gupta V, Bhatia BD. Correlation between clinical features and degree of immunosuppressant in HIV infected children. Indian Pediatr. 2008;45(2):140-3.

12. Crowe SM, Carlin JB, Stewart KI, Lucas CR, Hoy JF. Predictive value of CD4 lymphocyte numbers for the development of opportunistic infections and malignancies in HIV-infected persons. J Acquir Immune Defic Syndr. 1991;4(8):770-6. PMID: 1677419

13. Ghate MV, Mehendale SM, Mahajan BA, Yadav R, Brahme RG, Divekar AD, et al. Relationship between clinical conditions and CD4 counts in HIV-infected persons in Pune,
Maharashtra, India. Natl Med J India. 2000;13(4):183-7. PMID: 11002684

14. Sharma S, Dhungana GP, Pokhrel BM, Rijal BP. Opportunistic infections in relation to CD4 level among HIV seropositive patients from central Nepal. Nepal Med Coll J. 2010;12(1):1-4. PMID: 20677600

15. Sayad B, Hatami H, Janbakhsh A, Vaziri S, Afsharian M, Rezabeigi M. Survey of clinical syndromes leading to hospitalization in HIV infected patients according to CD4 count in Sina Hospital (Kermanshah). Avicenna J Clin Med. 2006;13(3):51-6. [Persian] 